\title{
Influence of wt. \% and Specific Area of HRGO Nanoplatelets on Behaviour and Processing Evolution of PMMA Bone Cement for Orthopaedic and Trauma Surgery
}

\author{
Ynés Yohana Pastor ${ }^{1,2}$, Jaime Orellana ${ }^{1}$, Fernando Calle ${ }^{3}$ and José Ygnacio Pastor ${ }^{1 *}$ \\ 1 Departamento de Ciencia de los Materiales-CIME, Universidad Politécnica de Madrid, Spain. \\ 2 Facultad de Medicina, Universidad Complutense de Madrid, Spain. \\ 3 Departamento de Ingeniería Electrónica-ISOM, Universidad Politécnica de Madrid, Spain. \\ * Correspondence: jy.pastor@upm.es.
}

\begin{abstract}
Bone cement, mainly based in poly(methyl methacrylate) (PMMA), is commonly used in different arthroplasty surgical procedures, and its use is essential for prosthesis fixation. However, its manufacturing process reaches high temperatures (up to $120^{\circ} \mathrm{C}$ ) that can produce necrosis in the patients' surrounding tissues. In order to contribute to avoid this problem, the addition of graphene could delay the polymerisation of the MMA and, simultaneously, favour the optimisation of the composite material's properties. In this work, we address the effect of different percentages of Highly Reduced Graphene Oxide (HRGO) with different wt. \% (0,10, 0,50 and 1,00) and surface densities (150, 300,500 and $750 \mathrm{~m}^{2} / \mathrm{g}$ ) on the physical, mechanical, and thermal properties of commercial PMMAbased bone cement and its processing. It was noticed that a lower sintering temperature is achieved with this addition, making it less harmful to use in surgery and as it reduces its adverse effects.
\end{abstract}

In contrast, the variation of the density of the materials does not introduce significant changes, which indicates that the addition of HRGO would not significantly increase the bone porosity. Lastly, the mechanical properties (strength, elastic modulus, fracture toughness) are reduced by almost $20 \%$. Nevertheless, their typical values are high enough so that these new materials can still fulfil their structural function.

Keywords: PMMA: Polymethylmethacrylate; HRGO: Highly Reduced Graphene Oxide; DSC: Differential Scanning Calorimetry; FESEM: Field Emission Scanning Electron Microscopy.

\section{Introduction}

Bone cement is a polymeric material commonly used as a structural adhesive to fix replacement prostheses when the bone is damaged [1]. Nowadays, the implantation of prostheses has become an increasingly common practice throughout the world, both due to the rise and ageing of the population and the higher incidence of obesity [2] and other pathologies such as arthrosis (whose global prevalence is around $47 \%$ [3]), rheumatoid arthritis, osteoarthritis and others. Therefore, the design of new optimised structural adhesives is an essential objective in traumatology and orthopaedics.

However, the limitation of biocompatibility and toxicity significantly reduces the variety of materials used as adhesives or bone cement for prostheses fixation. These materials are sintered directly in the operating room from two phases: a solid one, in powder form, composed mainly of poly-methylmethacrylate (PMMA) microspheres, benzoyl peroxide (BPO) as initiating agent, and barium sulphate $\left(\mathrm{BaSO}_{4}\right)$ as radiopacifier to allow it to be detected on control radiographs; and a liquid phase, mainly composed of methylmethacrylate (MMA), i.e. the monomer that reacts to form PMMA in a radical reaction, $\mathrm{N}$, $\mathrm{N}$-dimethyl-P-toluidine (DmpT) as a reaction accelerator, and hydroquinone as a stabiliser or inhibitor of the polymerisation reaction. 
After polymerisation of the bone cement, which usually takes a few minutes, residual MMA always remains, between 2-6\%. However, this amount decreases with time, stabilising after approximately one year to around $1-2 \%$ of residual MMA [1]. This is because the mobility of the monomer decreases exponentially with the increasing viscosity of the bone cement. That MMA residue, together with small PMMA particles released from the bone cement during the service life, activate an inflammatory cascade, where after the rupture of the endothelium and vasoconstriction of the area, potentially necrotic ischemia of chemical origin occurs.

Osteoclasts, the only cells capable of resorbing bone [4] through highly specialised structures [5], can respond to a wide variety of cytokines produced by cells of the innate and adaptive immune systems [6] [7] [8]. Particular subclasses of circulating monocytes and dendritic cells and progenitor cells of the monocyte-macrophage line resident in the bone marrow have the ability to transform into osteoclasts if they are subjected to specific inflammatory signals. Furthermore, the production and activation of T-lymphocytes cause a rise in osteoclast genesis and bone resorption since their interaction with the RANKL-RANK system increases osteoclast survival, delaying their apoptosis and making it possible for several cycles of osteoclastic activity [9]. All these inflammatory processes can lead to the loss of bone tissue, causing aseptic loosening, which accounts for approximately two-thirds of patients' revisions.

Graphene is a two-dimensional allotropic phase of carbon, ideally being a one-atomthick layer, characterised by some exceptional properties: a large specific surface 2630 $\mathrm{m}^{2} / \mathrm{g}$, an elasticity modulus of $1 \mathrm{TPa}$, a tensile strength of $130 \mathrm{GPa}$, great mechanical flexibility, excellent thermal conductivity, amongst others, and nominally biocompatible [10] [11] [12]. Therefore, adding graphene to commercial bone cement could improve the mechanical properties of the compound [13]. Additionally, the percentage of polymerisation from MMA to PMMA could be increased since graphene could inhibit the initiators, reducing the number of active polymerisation points, leading to slower but more efficient polymerisations of PMMA. In particular, highly reduced graphene oxide (HRGO) nanoplatelets are a derivative of graphene that is not entirely reduced and whose edges are highly reactive. Hydroxyl groups are formed on these limits, among other possible compounds, therefore acting as effective scavengers for polymerisation accelerators.

On the other hand, the MMA polymerisation reaction is highly exothermic, releasing $52-57 \mathrm{~kJ} / \mathrm{mol}$ of MMA, resulting in a heat release of $1.4-1.710^{8} \mathrm{~J} / \mathrm{m}^{3}$. Consequently, the bone cement is heated to high temperatures, between $70-120^{\circ} \mathrm{C}$. Thermal necrosis in tissues has been shown to occur at temperatures above $50{ }^{\circ} \mathrm{C}$ if it exceeds one minute and $45^{\circ} \mathrm{C}$ if it exceeds 30 minutes [14]. The minimum critical point of temperature to delay the death of osteocytes is around $47^{\circ} \mathrm{C}$, causing bone resorption, subsequent replacement, and medium and long-term disturbances in the anchorage of the implants [15] [16] [17] [18] [19] [20]. Acrylic bone cement is in intimate contact with bone, and exposure to high temperature can cause thermal necrosis in adjacent tissues. This can happen both due to direct cell damage with protein denaturation or to coagulation alterations that cause a lack of irrigation of the adjacent bone tissue, compromising the success of the surgery and additional healthcare costs. Besides, necrotic debris and tissues provide favourable conditions for bacterial growth and can eventually lead to abscess formation.

The structure and vascularity of bone play an essential role in the response of bone tissue to heat. Cancellous bone dissipates heat faster and has a greater capacity for regeneration than compact (cortical) bone, as it has a better supply of blood vessels. The addition of graphene to the bone cement could delay the polymerisation in a controlled way, and a reduction of the temperature rise and a longer workability time could be achieved by the surgeon.

Regarding mechanical properties, bone cement works well below its glass transition temperature, $\mathrm{T}_{\mathrm{g}}$, which implies a brittle-elastic behaviour. Analysed from the point of view of geometric stability over time, the fact that the bone cement works below $\mathrm{T}_{\mathrm{g}}$ is optimal, as creep processes are negligible during the useful life of the bone cement, esti- 
mated at fifteen years. The lower value of the elasticity modulus of the bone cement facilitates a more homogeneous and even distribution of stress on the bone, thus avoiding stress concentrations that may damage it.

Furthermore, the addition of graphene to the adhesive could optimise the toughness or energy of fracture. The propagation of cracks in the matrix could be impeded or diverted by the presence of graphene; this is because, locally, it would be more favourable to surround the nanoparticle than to fracture it. As the path of the crack increases and becomes more protracted and more tortuous, the energy necessary for the crack to grow and propagate increases [21] [22] [23].

Within this context, this work analyses the effect of the addition of different percentages of graphene $(0,10 \%, 0,50 \%$ and $1,00 \%)$ and several specific surface densities (150, 300,500 and $750 \mathrm{~m}^{2} / \mathrm{g}$ ) on the physical, mechanical and thermal properties, as well as in the processing of commercial PMMA-based bone cement.

\section{Materials, Manufacture and Characterisation}

In this study, a commercial bone cement widely used in traumatology was taken as reference material. DePuy Ibérica S.L. supplied the starting excipients with CMW-1 Radiopaque reference, and their composition is shown in Table 1 . The precursors are presented in two phases: i) solid phase, with poly-methylmethacrylate (PMMA) as the main bone cement compound, benzoyl peroxide (BPO) as initiating agent, and barium sulphate (BaSO4) as radio-opacifying agent; and ii) liquid phase, with the monomer methyl methacrylate (MMA), N, N-Dimethyl-p-toluidine (DmpT) as accelerator, and hydroquinone as stabiliser or inhibitor of the polymerisation reaction.

Table 1. Composition of DePuy Ibérica CMW 1 bone cement - Radio-opaque.

\begin{tabular}{|c|c|c|c|c|c|}
\hline \multicolumn{3}{|c|}{ Solid Phase } & \multicolumn{3}{|c|}{ Liquid Phase } \\
\hline Compound & Proportion & Function & Compound & Proportion & Function \\
\hline $\begin{array}{c}\text { Poly-methylmethacrylate } \\
\text { (PMMA) }\end{array}$ & 88,85 wt. $\%$ & Polymer & $\begin{array}{l}\text { Methyl methacrylate } \\
\text { (MMA) }\end{array}$ & 99,18 wt. $\%$ & Monomer \\
\hline Benzoyl peroxide (BPO) & 2,05 wt. $\%$ & Initiating agent & $\begin{array}{c}\text { N, N-Dimethyl-p-toluidine } \\
\text { (DmpT) }\end{array}$ & $\leq 0,82$ wt. $\%$ & Accelerator \\
\hline Barium sulphate $\left(\mathrm{BaSO}_{4}\right)$ & 9,1 wt. \% & $\begin{array}{c}\text { Radio- } \\
\text { opacifying agent }\end{array}$ & Hydroquinone & $25 \mathrm{ppm}$ & Stabilizer \\
\hline
\end{tabular}

To analyse the effect of graphene on the behaviour of the reference bone cement, four types of highly reduced graphene (HRGO) with different values of the specific area $\left(\mathrm{m}^{2} / \mathrm{g}\right)$ and proportions were used and supplied by XG Sciences. The characteristic values for these materials are shown in Table 2.

Table 2. Composition of XG Sciences Highly Reduced Graphene Oxide (HRGO).

\begin{tabular}{ccccc}
\hline Graphene & $\begin{array}{c}\text { Specific area } \\
\left(\mathbf{m}^{2} / \mathbf{g}\right)\end{array}$ & $\begin{array}{c}\text { Atomic oxygen } \\
\text { concentration } \mathbf{( \% )}\end{array}$ & $\begin{array}{c}\text { Mean } \\
\text { diameter }(\boldsymbol{\mu m})\end{array}$ & $\begin{array}{c}\text { Density } \\
\left(\mathbf{g} / \mathbf{c m}^{3}\right)\end{array}$ \\
\hline HRGO 120 & $120-150$ & $<1$ & 15 & $0,03-0,10$ \\
\hline HRGO 300 & 300 & 5 & $<2$ & $0,20-0,40$ \\
\hline HRGO 500 & 500 & 7 & $<2$ & $0,20-0,40$ \\
\hline HRGO 750 & 750 & 10 & $<2$ & $0,20-0,40$ \\
\hline
\end{tabular}

Its low oxygen content characterises HRGO. However, the greater the surface area, the more difficult it is to reduce the oxygen content due to the high reactivity of the graphene nanoplatelet edge. For this reason, although in Table 2, the oxygen content increases with the specific area, they all correspond to the same HRGO manufacturing procedure.

For the preparation of PMMA compounds with HRGO, a high-resolution Mettler-Toledo balance (up to $10^{-6} \mathrm{~g}$ ) was used so that the percentage of each component could be determined with very high precision. To achieve a good dispersion of the graphene in the 
PMMA, once the solid phase of the precursor was mixed with the graphene, this combination was stirred in an ultrasound bath at $4.000 \mathrm{~Hz}$ for five minutes. After that, the liquid phase was added, and the exothermic reaction started. Subsequently, the entire mixture was spread on a $100 \mathrm{~mm} \times 100 \mathrm{~mm}$ stainless steel mould whose support bases were coated with Teflon to avoid adhesions of the bone cement to the metal, making it easier to separate and avoid introducing undesirable mechanical deformations in the material. The amount of material deposited was calculated so that the resulting plate had a thickness of about 2,4 to 3,0 $\mathrm{mm}$, like the thickness of the bone cement layer used in trauma operating rooms to fix the prosthesis to the bone.

Next, as shown in Figure 1, by employing an electromechanical testing machine (Instron $5866, \mathrm{~GB})$, a pressure of $50 \mathrm{kPa}$ has been exerted perpendicular to the mould surfaces to simulate the pressures at which bone cement is subjected to through a finger or scalpel in operating rooms [1] and to homogenise the manufacturing conditions of the material [24] [23] [25] [26].

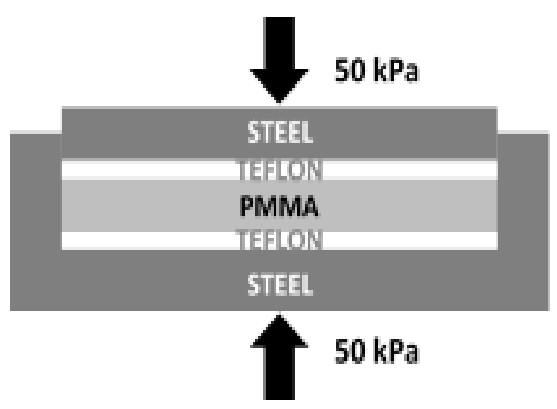

Figure 1. Application of pressure during the curing of the bone cement.

Although the charge was initially maintained for $20 \mathrm{~min}$ to follow the preparation times indicated by the manufacturer, it was observed that the graphene content influences the polymerisation time; therefore, in some cases, it was necessary to maintain the charge for more than $24 \mathrm{~h}$ until the end of the polymer synthesis. Once the desired state in the bone cement was reached, the load was removed, the bone cement detached from the mould, and the material stored in hermetically sealed PET zip-bags at room temperature for one year before testing. Table 3 shows the specific composition and nomenclature used for each of the nine new manufactured materials.

Table 3. Nomenclature of bone cement compositions with HRGO manufactured in the form of $100 \times 100 \times 5 \mathrm{~mm}^{3}$ plates.

\begin{tabular}{ccccc} 
& \multicolumn{4}{c}{ Surface area of the graphene used $\left(\mathbf{m}^{2} / \mathbf{g}\right)$} \\
\hline $\begin{array}{c}n \\
\text { HRGO weight } \\
\text { percentage (wt. } \%)\end{array}$ & $\mathbf{1 2 0}$ & 300 & 500 & 750 \\
\hline $\mathbf{0 , 1}$ & G120-0.1 & G300-0.1 & - & G750-0.1 \\
\hline $\mathbf{0 , 5}$ & - & G300-0.5 & - & - \\
\hline $\mathbf{1 , 0}$ & G120-1.0 & G300-1.0 & G500-1.0 & G750-1.0 \\
\hline
\end{tabular}

\subsection{Physical characterisation}

The density of each material was determined using the Archimedean immersion method in distilled water at a controlled temperature, using a Mettler-Toledo balance with an LC-P Density unit attached to measure the masses. The nominal dimensions of the test pieces were $26,8 \times 3,0 \times 2,4 \mathrm{~mm}$. Six tests were carried out for each composition, in which one of them used five test tubes from different areas to identify possible inhomogeneities in the developed material. 


\subsection{Thermal characterisation}

Differential Scanning Calorimetry (DSC) was used to determine the glass transition temperature $\left(\mathrm{T}_{\mathrm{g}}\right)$ and the amount of residual monomer in the new materials. For this, a Mettler Toledo DSC822e machine with STARe software was used. Samples of $6 \mathrm{mg}$ were submitted to a heating ramp of $10^{\circ} \mathrm{C} / \mathrm{min}$ between 20 and $200{ }^{\circ} \mathrm{C}$. To achieve cooling at the same speed, liquid nitrogen was used as a refrigerant.

\subsection{Mechanical characterisation: tensile tests}

To determine the tensile strength $\left(\sigma_{t}\right)$ and the modulus of elasticity $(E)$ of the new materials, simple tensile tests were carried out in an electromechanical testing machine with a $\pm 1 \mathrm{kN}$ load cell (resolution lower than $\pm 0,1 \mathrm{~N}$ ) and with an LVDT type extensometer with a path of $\pm 1 \mathrm{~mm}$ (resolution lower than $\pm 1 \mu \mathrm{m}$ ). The tests were carried out in displacement control with a speed of $100 \mu \mathrm{m} / \mathrm{min}$ and an initial preload of 5,0 N. This preload is intended to achieve the perfect alignment of the specimen and ball joints of the loading device and thus avoid possible twisting or rotations on the sample, which would lead to inaccurate results.

The specimens for these tests were machined in the shape of a dog bone specimen with nominal dimensions of $10 \mathrm{~mm}$ testing length, $30 \mathrm{~mm}$ total length $(L T)$, and $5 \mathrm{~mm}$ width at the heads inside the jaws, $25 \mathrm{~mm}$ centre shaft $\left(L_{0}\right), 3 \mathrm{~mm}$ is the thickness of the zone of the specimen with a reduced section $(A)$, and $2,4 \mathrm{~mm}$ thickness $(\boldsymbol{B})$. For each material composition, the samples indicated in Table 3 were tested. To calculate the value of the maximum tensile strength $(\sigma t)$, the following formula was used [27]:

$$
\sigma=\frac{F_{m}}{A \cdot B}
$$

where $\boldsymbol{F}_{m}$ is the maximum force obtained during the tensile test. At least six tests were performed for each composition and the mean value and its root mean square error were obtained.

\subsection{Mechanical characterisation: fracture toughness}

The same mechanical testing instruments mentioned above were used, although three-point bending tests were performed on specimens notched with $0,13 \mathrm{~mm}$ diameter diamond wire to determine fracture toughness $\left(K_{I C}\right)$. In this case, the specimens had a preload of $1 \mathrm{~N}$ and were tested at a speed of $100 \mu \mathrm{m} / \mathrm{min}$ in displacement control. This time, the experimental device consisted of a system of alumina rollers, $5 \mathrm{~mm}$ in diameter, with a span between supports of $20 \mathrm{~cm}$.

The nominal dimensions of the parallelepipedal specimens were: length $26,8 \mathrm{~mm}$; width 3,0 $\mathrm{mm}$; and edge 2,4 $\mathrm{mm}$. As in the previous case, before each test, the dimensions of each specimen were measured with a calliper with a resolution of $\pm 0,01 \mathrm{~mm}$. The nominal length of the notches was $1,1 \mathrm{~mm}$ and was determined with a NIKON Profile Projector $\mathrm{V}-12 \mathrm{~B}$, with a resolution of $\pm 0,001 \mathrm{~mm}$.

Finally, to calculate the fracture toughness from the maximum load and the dimensions of the specimens [28], the following equation was used:

$$
\begin{aligned}
& \qquad K_{I C}=\sigma \cdot(\pi \cdot a)^{1 / 2} \cdot Y\left(\frac{a}{h}\right) \quad \text { where } \\
& Y\left(\frac{a}{h}\right)=1,106-1,552\left(\frac{a}{h}\right)+7,71\left(\frac{a}{h}\right)^{2}-13,53\left(\frac{a}{h}\right)^{3}+14,23\left(\frac{a}{h}\right)^{4} \text { is a geometric factor, } \\
& \sigma=\frac{6 M}{b \cdot h^{2}} \text { is the breaking stress, } \\
& M=\frac{F \cdot L}{4} \text { is the maximum moment generated from the fracture force, }
\end{aligned}
$$

$\boldsymbol{a}$ is the length of the notch, $\boldsymbol{b}$ is the width of the sample, $\boldsymbol{h}$ is the edge of the sample, $\boldsymbol{L}$ is the distance between supports, and $\boldsymbol{F}$ is the maximum fracture force.

At least six tests were performed for each composition and the mean value and its root mean square error were obtained. 


\subsection{Microstructural and fractographical analysis}

For the analysis of microstructures and the fracture surfaces of the studied materials, a Zeiss optical microscope and a very high-resolution field emission scanning electron microscope (Auriga series, Zeiss) were used. To study the samples in the scanning electron microscope, the test tubes were fixed to copper support with silver paint and were made conductive by deposition of a nanometric layer (about $26 \mathrm{~nm}$ ) of carbon in a LEICA EM ACE600 metalliser.

\section{Results and discussion}

Given the high number of experimental results obtained and the interrelationship between them, this section will show the results for each of the characterisations carried out, followed by a brief discussion. Finally, from the microstructural and fractographic analysis of the materials, an integrative discussion will be made of the macroscopical results obtained concerning the deformation and fracture micromechanisms observed at the microscale. It is intended to establish a correlation between microstructure and properties that allows the optimisation of future materials.

In all the physical and mechanical characterisation shown below, each experimental point corresponds to at least six measurements, and the error interval is the mean square error. In the thermal characterisation, only one measurement could be made for each experimental point.

\subsection{Physical characterisation}

Table 4 shows the variation of the density of each material, $\rho$, dependent on the percentage and area of the added HRGO. The displayed results show the mean value and root mean square error of at least six measurements. The error obtained in determining the density was, in almost all cases, less than $0,7 \%$, which has made it possible to detect minimal variations in density with the addition of HRGO.

Table 4. Materials' density versus the percentage and surface area of the added HRGO. Each result shows the mean value and root mean square error.

\begin{tabular}{ccccc} 
& \multicolumn{4}{c}{$\rho\left(\mathrm{g} / \mathrm{cm}^{3}\right)$} \\
\cline { 2 - 5 } & \multicolumn{4}{c}{ Surface area of the graphene used $\left(\mathbf{m}^{2} / \mathbf{g}\right)$} \\
\hline HRGO weight percentage (wt. $\mathbf{\%})$ & $\mathbf{1 2 0}$ & 300 & $\mathbf{5 0 0}$ & $\mathbf{7 5 0}$ \\
\hline $\mathbf{0 , 0}$ & \multicolumn{4}{c}{$1,244 \pm 0,002[23]$} \\
\hline $\mathbf{0 , 1}$ & $1,240 \pm 0,004$ & $1,240 \pm 0,002$ & - & $1,182 \pm 0,007$ \\
\hline $\mathbf{0 , 5}$ & - & $1,229 \pm 0,009$ & - & - \\
\hline $\mathbf{1 , 0}$ & $1,241 \pm 0,003$ & $1,236 \pm 0,003$ & $1,230 \pm 0,006$ & $1,234 \pm 0,004$ \\
\hline
\end{tabular}

Since the density of the graphene used is much lower than that of PMMA, it was expected that the density of the composite material would be reduced. Although the graphene addition rates only reach $1 \%$, the expected reduction due to this effect using the rule of mixtures should be less than that percentage. Conversely, the possibility of HGRO platelets acting as pore generation points suggests that this can also reduce the final density. In Table 4, an increase in the surface density of graphene tends to reduce the volumetric density of the compound, which would confirm the hypothesis that the greater the surface area of the HGRO, the more likely it is that nucleation of pores will occur around the platelets. The only exception is for G750-0.1, whose density is much lower than expected what indicates that there probably was a problem during the synthesis of the material that resulted in more porosity than likely.

The reduction in density due to the weight percentage of graphene is so slight that it is within the measurements' error limits. Again, the most remarkable singularity is found in G750-0.1, which leads us to think that perhaps there was some small error during the 
processing of this material, which contributed to reducing the density in a more significant proportion than expected rest of the results.

\subsection{Thermal characterisation}

Table 5 shows the evolution of the glass transition temperature $\left(T_{g}\right)$ depending on the percentage and surface area of the added HRGO. As it can be seen, this parameter is not much clearly affected by the presence of HGRO since random values appear around the value for PMMA without HGRO. So, it can be considered almost independent of the presence of HRGO, at least in the proportions in which it was used and at long ageing times.

Table 5. Glass transition temperature $(\mathrm{Tg})$ versus the percentage and surface area of the added HRGO.

\begin{tabular}{ccccc} 
& \multicolumn{5}{c}{$\mathrm{T}_{\mathrm{g}}\left({ }^{\circ} \mathrm{C}\right)$} \\
\cline { 2 - 5 } & \multicolumn{4}{c}{ Surface area of graphene used $\left(\mathbf{m}^{2} / \mathbf{g}\right)$} \\
\hline HRGO weight percentage (wt. $\%)$ & $\mathbf{1 2 0}$ & $\mathbf{3 0 0}$ & $\mathbf{5 0 0}$ & $\mathbf{7 5 0}$ \\
\hline $\mathbf{0 , 0}$ & \multicolumn{5}{c}{$69,6[15]$} \\
\hline $\mathbf{0 , 1}$ & 70,2 & 69.8 & - & 70.2 \\
\hline $\mathbf{0 , 5}$ & - & 68.0 & - & - \\
\hline $\mathbf{1 , 0}$ & 68.3 & 69.3 & 70.8 & 70.3 \\
\hline
\end{tabular}

Something very different happens with the residual monomer, as can be seen in Table 6. A maximum of residual monomer is obtained with $300 \mathrm{~m}^{2} / \mathrm{g}$ and $0,5 \mathrm{wt}$. \%, indicated in Figure 2. This maximum is in the middle of the studied values, and we can see a clear trend with a central maximum and a decrease in residual monomer by increasing or decreasing the wt. \% or the specific area of HRGO. This leads us to think that two mechanisms may facilitate MMA polymerisation for long ageing times. Graphene is known to act as an inhibitor of the radical initiator of the radical polymerisation of MMA, as it has a more significant amount of available double bonds compared to GO. Thus, an increase of the HRGO edge, either by increasing the wt. \% or the specific area may result in a higher inhibition of the radicals initiating the reaction. Therefore, it is more unlikely that the MMA encounters a radical to polymerise and obtaining a higher residual MMA, as shown by our results in the range of 0.1 to $0.5 \mathrm{wt} . \%$ and 120 to $300 \mathrm{~m}^{2} / \mathrm{g}$. However, this does not explain the observations for high $\mathrm{HRGO}, 750 \mathrm{~m}^{2} / \mathrm{g}$ and $1.0 \mathrm{wt}$. \%, where the residual MMA decreases in the long term. To explain this exciting result, we must consider the ease of MMA to diffuse within the polymer itself, this being simpler the fewer polymeric chains there are in the polymer microstructure. The HRGO edge acts as an inhibitor of nucleation points, and the higher the HRGO and the more significant specific area, the greater the reactive border that inhibits the radicals. If a large part of these radicals were inhibited, we would have reached a situation where there would have been fewer polymer chains, allowing them to slip easily and the MMA to reach one of the reactive points. Reducing the amount of residual monomer is relevant from a clinical perspective, as the potential toxicity caused by MMA is well known [29].

Table 6. Residual monomer MMA (\%) versus the percentage and surface area of the added HRGO.

\begin{tabular}{ccccc}
\cline { 2 - 5 } & \multicolumn{4}{c}{ Residual MMA (\%) } \\
\cline { 2 - 5 } & \multicolumn{4}{c}{ Surface area of graphene used $\left(\mathbf{m}^{2} / \mathbf{g}\right)$} \\
\hline HRGO weight percentage (wt. $\%)$ & $\mathbf{1 2 0}$ & $\mathbf{3 0 0}$ & $\mathbf{5 0 0}$ & $\mathbf{7 5 0}$ \\
\hline $\mathbf{0 , 1}$ & 0,67 & 0,1 & 0,67 & 0,1 \\
\hline $\mathbf{0 , 5}$ & - & 0,5 & - & 0,5 \\
\hline $\mathbf{1 , 0}$ & 1,05 & 1,0 & 1,05 & 1,0 \\
\hline
\end{tabular}


In addition, the inhibition of radicals induces a slower polymerisation, thus reducing the rate of energy release and the escalation in temperature and increasing the curing time, something which we observed in previous studies [26]. This effect would control the clinical needs of curing time and local temperature production by choosing the suitable percentage and density of HRGO. In this way, it would be possible to limit thermal damage to the surrounding tissues during surgery and increase the material's working time according to surgical needs.

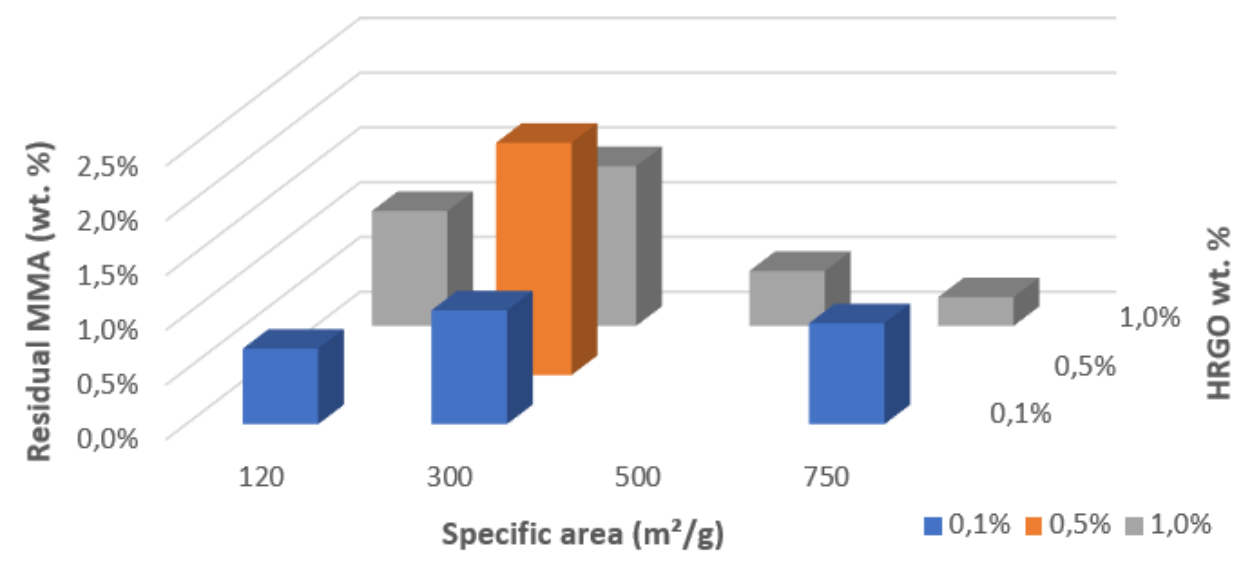

Figure 2. Residual monomer (MMA) versus specific area and percentage (blue $=0,1 \%$, orange $=$ $0,5 \%$, and grey $=1,0 \%$ ) by weight of the HRGO.

\subsection{Mechanical characterisation}

From the simple tensile tests, the stress-strain curves of these materials were obtained, which in all cases showed a macroscopically elastic and brittle behaviour until breaking. Therefore, the tensile strength, $\sigma t$, and the modulus of elasticity, $E$, were determined, as shown in Tables 7 and 8, respectively. In addition, from the mechanical bending tests at three points on notched specimens, the fracture toughness, KIC, was determined, which is shown in Table 9.

Table 7. Tensile strength, $\sigma_{t}$, of the material versus the percentage and surface area of the added HRGO. Each result shows the mean value and root mean square error.

\begin{tabular}{ccccc}
\cline { 2 - 5 } & \multicolumn{5}{c}{$\sigma_{\mathrm{t}}(\mathbf{M P a})$} \\
\cline { 2 - 5 } & \multicolumn{4}{c}{ Surface area of the graphene used $\left(\mathbf{m}^{2} / \mathbf{g}\right)$} \\
\hline HRGO weight percentage $(\mathbf{w t .} \mathbf{\%})$ & $\mathbf{1 2 0}$ & $\mathbf{3 0 0}$ & $\mathbf{5 0 0}$ & $\mathbf{7 5 0}$ \\
\hline $\mathbf{0 , 0}$ & \multicolumn{5}{c}{$38 \pm 2[23]$} \\
\hline $\mathbf{0 , 1}$ & $39 \pm 7$ & $36 \pm 4$ & - & $37 \pm 4$ \\
\hline $\mathbf{0 , 5}$ & - & $31 \pm 5$ & - & - \\
\hline $\mathbf{1 , 0}$ & $30 \pm 5$ & $29 \pm 3$ & $29 \pm 5$ & $20 \pm 1$ \\
\hline
\end{tabular}


Table 8. Modulus of elasticity, E, of the material versus the percentage and surface area of the added HRGO. Each result shows the mean value and root mean square error.

\begin{tabular}{ccccc} 
& \multicolumn{5}{c}{ E (GPa) } \\
\cline { 2 - 5 } & \multicolumn{4}{c}{ Surface area of the graphene used $\left(\mathbf{m}^{2} / \mathbf{g}\right)$} \\
\hline HRGO weight percentage (wt. $\%)$ & $\mathbf{1 2 0}$ & $\mathbf{3 0 0}$ & $\mathbf{5 0 0}$ & $\mathbf{7 5 0}$ \\
\hline $\mathbf{0 , 0}$ & \multicolumn{4}{c}{$3,20 \pm 0,02[23]$} \\
\hline $\mathbf{0 , 1}$ & $3.2 \pm 0,6$ & $3,2 \pm 0,2$ & - & $3,0 \pm 0,2$ \\
\hline $\mathbf{0 , 5}$ & - & $2,8 \pm 0,3$ & - & - \\
\hline $\mathbf{1 , 0}$ & $3,1 \pm 0,1$ & $2,8 \pm 0,3$ & $2,3 \pm 0,2$ & $2,2 \pm 0,3$ \\
\hline
\end{tabular}

Table 9. Fracture toughness, KIC, of the material versus the percentage and surface area of the added HRGO. Each result shows the mean value and root mean square error.

\begin{tabular}{ccccc} 
& \multicolumn{5}{c}{ KIC $\left(\mathbf{M P a . m}{ }^{1 / 2}\right)$} \\
\cline { 2 - 5 } & \multicolumn{4}{c}{ Surface area of the graphene used $\left(\mathbf{m}^{2} / \mathbf{g}\right)$} \\
\hline HRGO weight percentage (wt. $\mathbf{\%})$ & $\mathbf{1 2 0}$ & $\mathbf{3 0 0}$ & $\mathbf{5 0 0}$ & $\mathbf{7 5 0}$ \\
\hline $\mathbf{0 , 0}$ & & $1,28 \pm 0,02[23]$ & \\
\hline $\mathbf{0 , 1}$ & $1,40 \pm 0,02$ & $1,40 \pm 0,02$ & $1,40 \pm 0,02$ & $1,40 \pm 0,02$ \\
\hline $\mathbf{0 , 5}$ & - & - & - & - \\
\hline $\mathbf{1 , 0}$ & $1,08 \pm 0,03$ & $1,08 \pm 0,03$ & $1,08 \pm 0,03$ & $1,08 \pm 0,03$ \\
\hline
\end{tabular}

In all these experimental results, the increase of the HRGO contribution, either in percentage or in surface density, leads to a degradation of all the analysed mechanical properties, likely due to a decrease in the internal cohesion among the platelets. It would justify that the resistance capacity of the compound is reduced significantly, even in tiny percentages, for the three analysed parameters. This phenomenon could become an inconvenience for the clinical application of these materials, as it is well known that fracture toughness is essential for fatigue life. However, the fact that the mechanical properties of the bone cement are inferior to those of the bone and the prosthesis guarantees that, in case of overload, the breakage is produced by this element, which is the most easily replaceable.

\subsection{Microstructural and fractographic characterisation}

The microstructural and fractographic analysis of the studied materials showed that, in some cases, large pores had been trapped inside the material, as can be seen in Fig. 3. In the same image, it can be appreciated that the fracture surface is relatively flat. The former may explain the abnormally low-density values of G750-0.1, while the latter is compatible with the brittle elastic behaviour observed macroscopically for these materials. Nevertheless, Figure 4 show the typical porosity distribution, usually micrometric pores or smaller, and the barium sulphate radiopacifier appears as a uniformly dispersed white contrast in the PMMA matrix. 


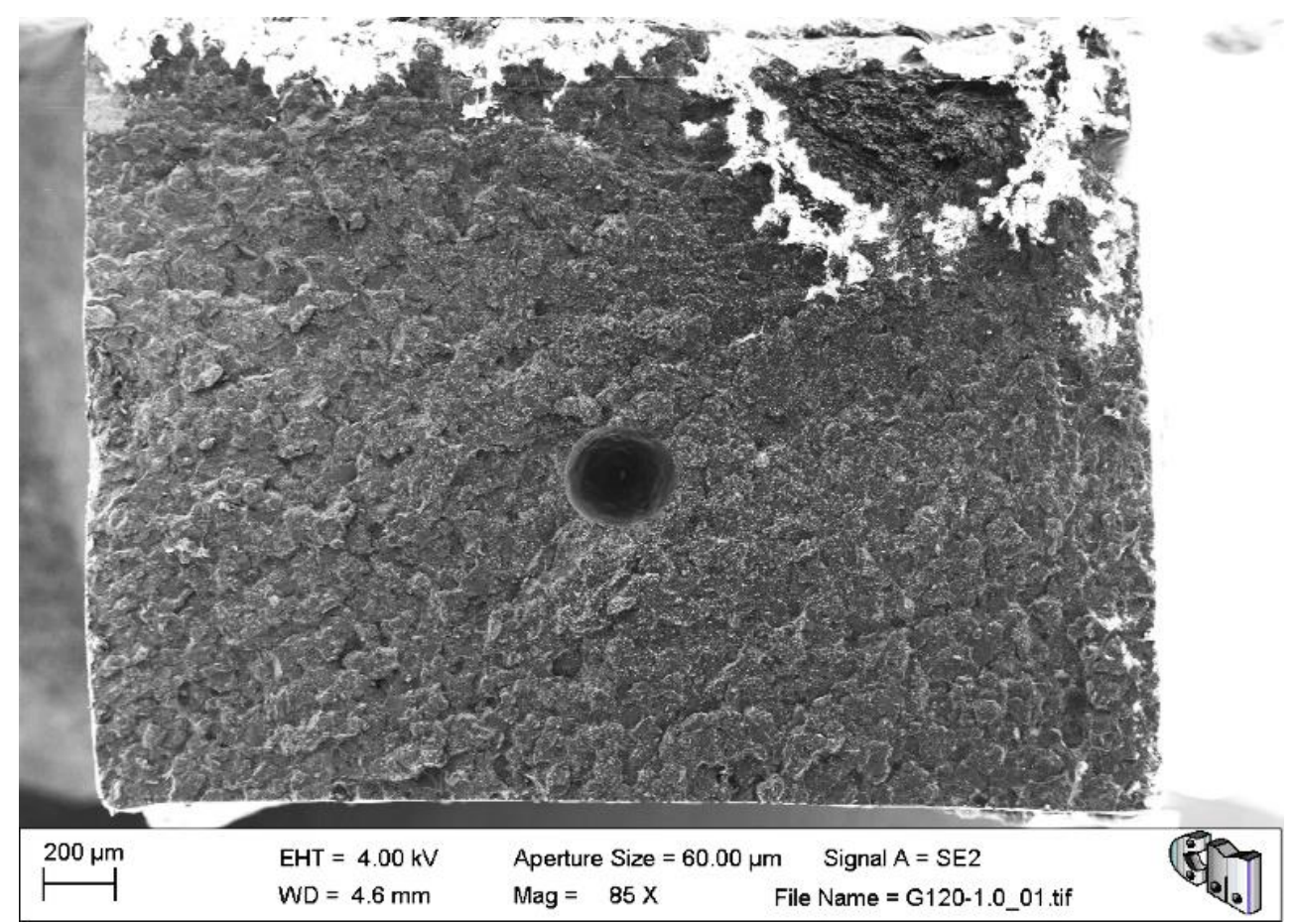

Figure 3. SEM image of the tensile fracture surface of G120-0.1. A giant air bubble can be seen trapped within the bone cement.
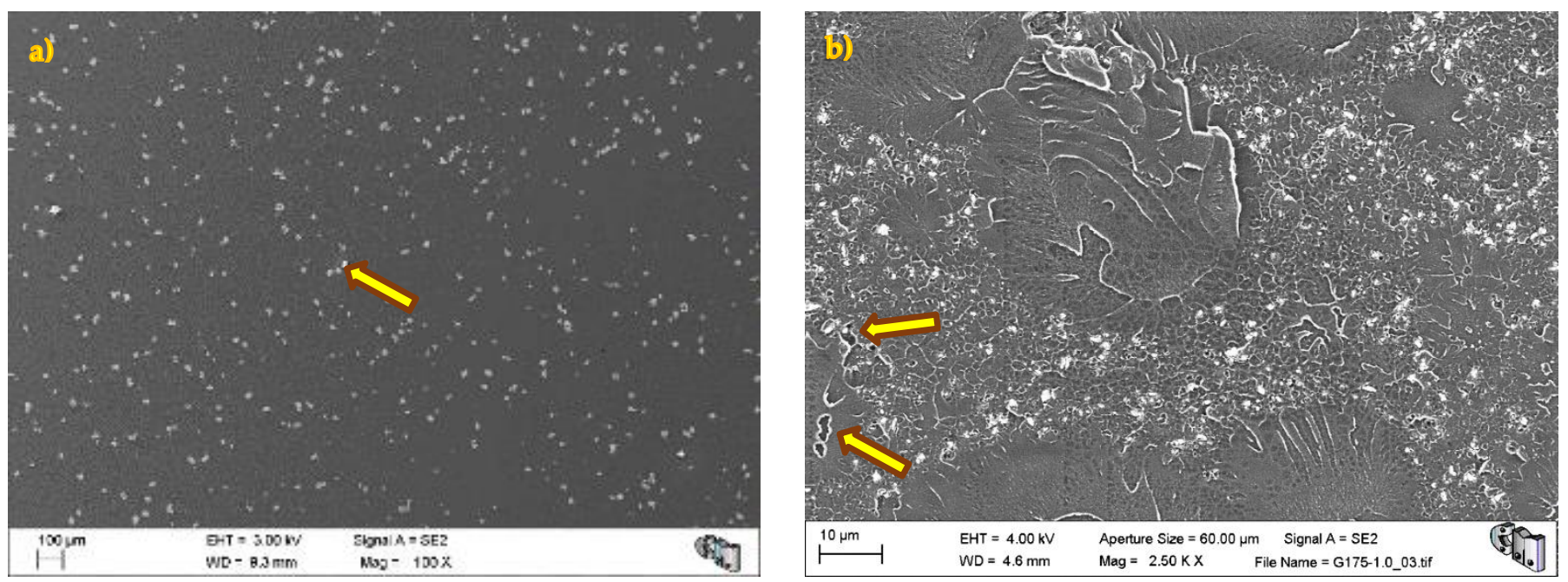

Figure 4. Microstructure of G120-0.1: a) at low magnification, the barium sulphate radiopacifier appears as a uniformly dispersed white contrast in the PMMA matrix; b) at higher magnification, some tiny pores and defects can be observed.

During detailed analysis of the fracture surfaces, poor adhesion of HRGO to bone cement (Figures 5 and 6) and the existence of unwanted agglomerates of HRGO (Figure 7) were observed for all the materials. Both factors lead to the creation of cracks and defects around the HRGO platelets.

A more significant number of cracks increases the likelihood of any of them reaching the critical crack size and propagating catastrophically under less stress than the expected critical value. For example, Figure 7 shows an HRGO lamella utterly parallel to the fracture surface. The gap between the bone cement and that HRGO lamella, or between HRGO lamellae, could have been a place where crack propagation started in this case. 
Consequently, both factors indicate that the presence of HRGO in the PMMA matrix justifies the macroscopic degradation of the mechanical behaviour of the composite observed in the previous section.
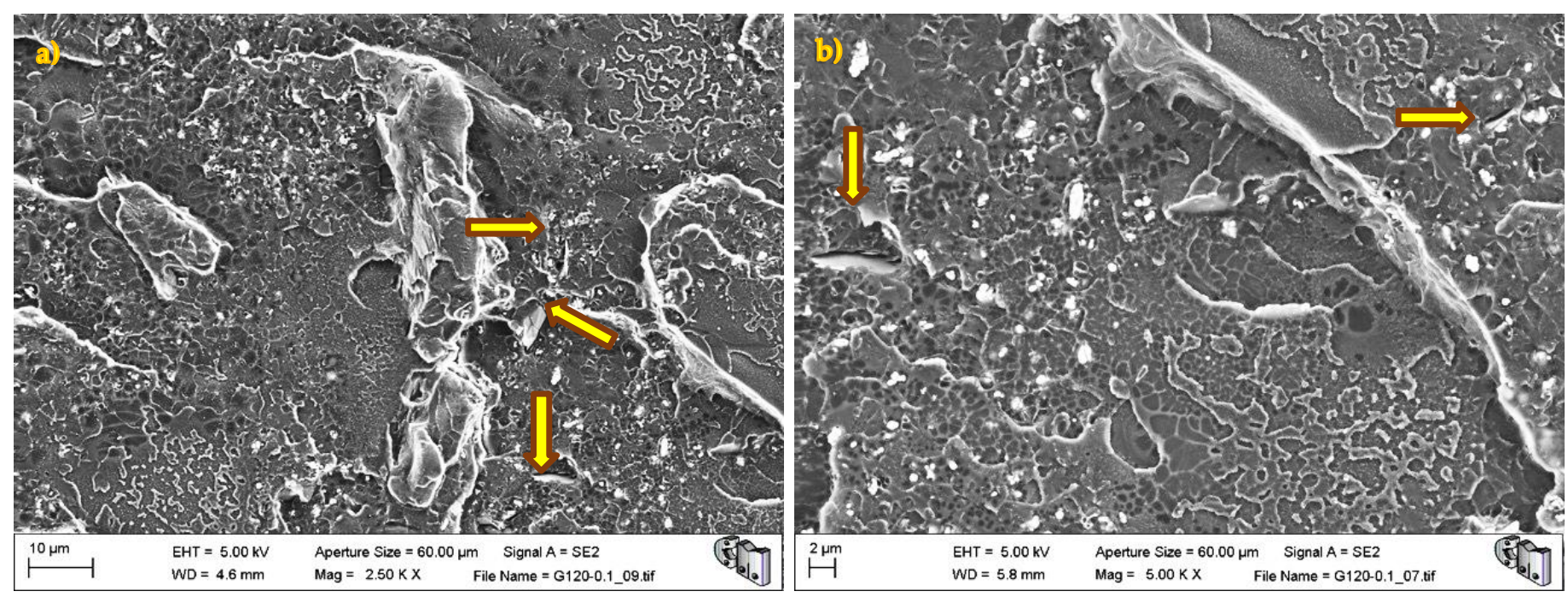

Figure 5. G120-0.1 fracture surface. The arrows indicate voids between the bone cement and the HRGO due to poor adhesion between the two: a) lower magnification; b) higher magnification.
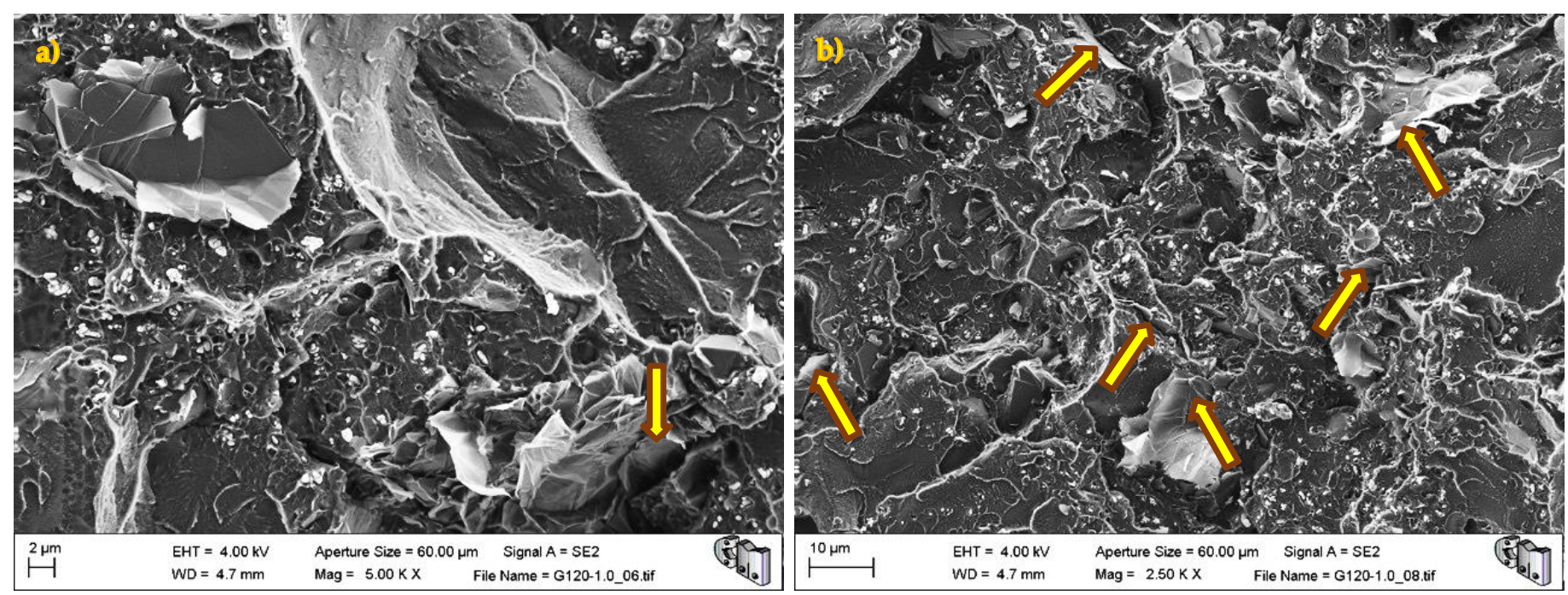

Figure 6. G120-1.0 fracture surface. The arrows indicate voids between the bone cement and the HRGO due to poor adhesion between both: a) higher magnification b) lower magnification. 

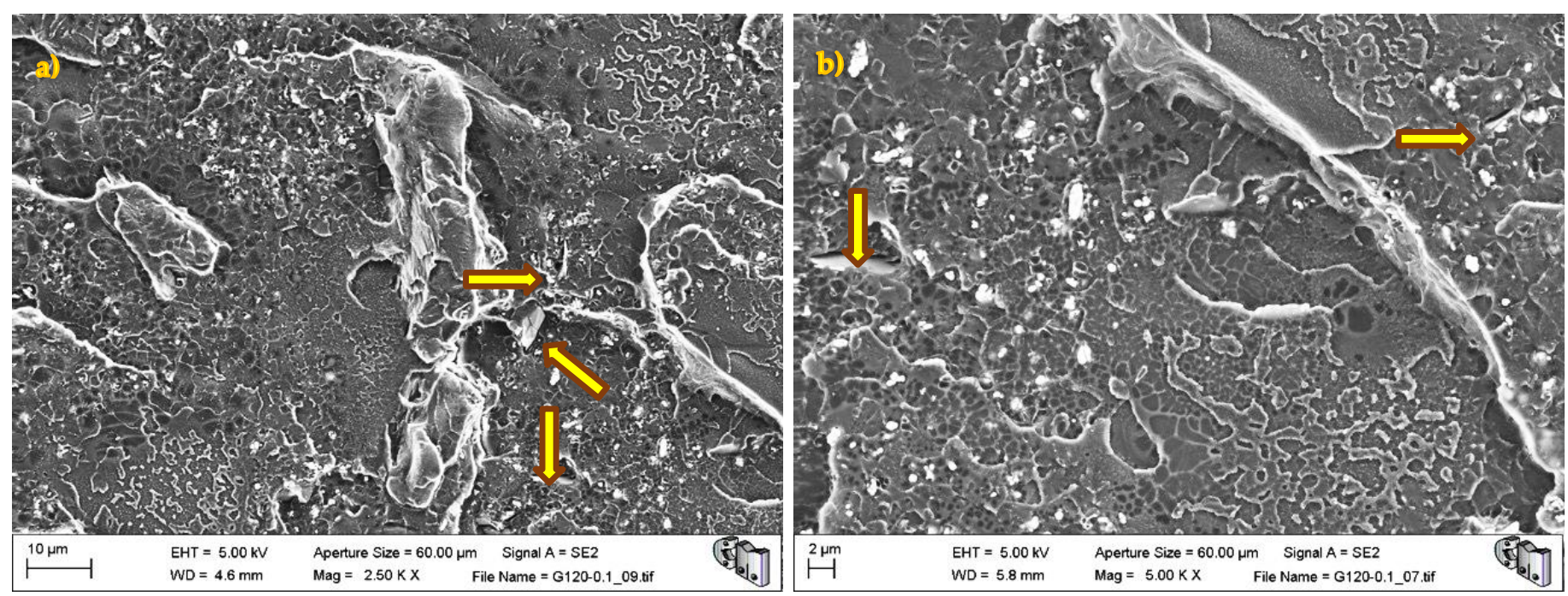

Figure 7. G120-1.0 fracture surface with an HRGO agglomerate perpendicular to the fracture surface: a) lower magnification. b) higher magnification.

\section{Conclusions}

From the experimental observations shown above and their discussion, the following conclusions can be established:

1. After one year of natural ageing, density and glass transition temperature are not affected by the addition of different percentages and surface densities of HGRO.

2. The amount of residual MMA varies with the amount of HRGO and its specific area. This phenomenon is related to reducing the polymerisation rate in the presence of HRGO and the MMA diffusivity inside the PMMA. It would allow controlling the curing time and the local temperature increases, which would help limit the thermal damage caused to surrounding tissues during surgery and increase the working time of the material if necessary.

3. Due to the addition of different percentages and surface densities of HGRO, the analysed mechanical properties suffer an intense degradation, exceeding $40 \%$.

4. To improve the mechanical behaviour of these compounds, it is essential to find micromechanisms that increase the cohesion between HRGO and the PMMA matrix, like the silanisation of graphene.

5. Looking ahead, it would be interesting to extend this study to lower concentrations of HGRO, consider the influence of HGRO on the bacterial colonisation of cement, analyse the evolution of the physical, thermal, and mechanical behaviour of bone cement with graphene after its controlled immersion in physiological serum, and study the influence on antibiotic release when added to bone cement.

\section{Author Contributions}

Conceptualisation, Y.Y.P., J.O. and J.Y.P.; methodology, Y.Y.P., J.O. and J.Y.P.; mechanical testing, J.O..; formal analysis, Y.Y.P.; investigation, Y.Y.P. and J.O.; resources J.Y.P.; writing - original draft preparation, Y.Y.P.; writing - review and editing, Y.P., J.O., F.C. and J.Y.P.; visualisation, Y.Y.P.; validation, F.C. and J.Y.P.; supervision, F.C. and J.Y.P.; project administration, J.Y.P.; funding acquisition, J.Y.P. and F.C. All authors have read and agreed to the published version of the manuscript.

\section{Funding}


This work has been supported by the Spanish Government (PID2019-106631GB-C44, MICINN/FEDER, UE) and Comunidad de Madrid Government (P2018/NMT-4511 NMAT2D-CM, P2018/NMT-4411 ADITIMAT-CM, FEDER-UE). J. Orellana thanks scholarship provided by UPM and Ministerio de Educación, Cultura y Deporte of Spain (FPU17/02035). Y.Y. Pastor thanks Prof. J. Marco (UCM) for his continuous encouragement.

\section{Conflicts of Interest}

The authors declare no conflict of interest.

\section{References}

[1] K. Klaus-Dieter, PMMA Cements, Springer, 2013.

[2] S. Harms, R. Larson, A. E. Sahmoun, and J. R. Beal, "Obesity increases the likelihood of total joint replacement surgery among younger adults," Int. Orthop., vol. 31, no. 1, p. 23-26, 2007.

[3] D. Vedia, D., L. Limachi, "Prevalence of radiological osteoarthritis in patients who attended, the Faculty of Technological Sciences of Health, management 2016 Sucre," Rev. Cien. Tec. In., vol. 16, no. 18, pp. 39-44, 2018.

[4] M. Asagiriab, H. Takayanagi, "The molecular understanding osteoclast differentiation," Bone, vol. 40, no. 2, pp. 251-264, 2007.

[5] J. Bilezikian, T. J. Martin, T. Clemens, C. Rosen, Principles of Bone Biology, Elsevier, 2008.

[6] L. Arboleya, S. Castañeda, "Osteoinmunología: el estudio de la relación entre el sistema inmune y el tejido óseo," Reumatología Clínica, vol. 9, no. 5, pp. 303-315, 2013.

[7] D. Jones, L. H. Glimcher, A.O. Aliprantis, "Osteoimmunology at the nexus of arthritis, osteoporosis, cancer, and infection," J. Clin. Invest., vol. 121, no. 7, p. 2534-2542, 2011.

[8] W. Feng, W. Xia, Q. Ye, W. Wu, "Osteoclastogenesis and osteoimmunology," Frontiers in Bioscience-Landmark, vol. 19, no. 5, pp. 758-767, 2014.

[9] G. del Nero-Viera, "Resorption as an inflammatory process. An approach to the pathogenesis," RCOE, vol. 10, no. 5-6, pp. 35-44, 2005.

[10] D. Chen, H. Feng, J. Li, "Graphene Oxide: Preparation, Functionalisation, and Electrochemical Applications," Chem. Rev., vol. 112, no. 11, p. 6027-6053, 2012.

[11] J.M. Munueraa, J.I. Paredesa, S.Villar-Rodila, M.Ayán-Varelaa, A. Pagánb, S.D. Aznar-Cervantesb, J.L. Cenisb, A. Martínez-Alonsoa, J.M.D. Tascóna, "High quality, low oxygen content and biocompatible graphene nanosheets obtained by anodic exfoliation of different graphite types," Carbon, vol. 94, no. 11, pp. 729-739, 2015.

[12] J.M. Parente, P. Santosa, S. Valveza, M.P. Silvaa, P.N.B. Reisa, "Fatigue behaviour of graphene composites: An overview," Procedia Structural Integrity, vol. 25, pp. 282-293, 2020.

[13] M.E. Valencia Zapata, L.M. Ruiz Rojas, J. Mina, J. Delgado-Ospina, C.D. Grande Tovar, "Acrylic Bone Cements Modified with Graphene Oxide: Mechanical, Physical, and Antibacterial Properties," Polymers, vol. 12, no. 8, pp. 1773-89, 2020.

[14] R. Wächter, P. Stoll, "Increase of temperature during osteotomy. In vitro and in vivo investigations," Int. J. Oral Maxillofac. Surg., vol. 20, no. 4, pp. 245-249, 1991.

[15] J. Lundskog, "Heat and bone tissue. An experimental investigation of the thermal properties of bone and threshold levels for thermal injury," Scand. J. Plast. Reconstr. Surg., vol. 9, pp. 1-80, 1972. 
[16] J. L. L. Linder, "Incorporation of stainless steel, titanium and Vitallium in bone," Injuty, vol. 6, no. 4, pp. 277-85, 1975.

[17] P.I. Brånemark, B.O. Hansson, R. Adell, U. Breine, J. Lindström, O. Hallén, A. Ohman, “Osseointegrated implants in the treatment of the edentulous jaw. Experience from a 10-year period," Scand. J. Plast. Reconstr. Surg. Suppl., vol. 16, no. 1, pp. 1-132, 1977.

[18] A.T. Berman, J.S. Reid, D.R. Yanicko Jr, G.C. Sih, M.R. Zimmerman, "Thermally induced bone necrosis in rabbits. Relation to implant failure in humans," Clin. Ortho.p Relat. Res., vol. 186, no. 6, pp. 284-92, 1984.

[19] A.R. Eriksson, T. Albrektsson, B. Albrektsson, "Heat caused by drilling cortical bone. Temperature measured in vivo in patients and animals," Acta Orthop. Scand., vol. 55, no. 6, pp. 629-31, 1984.

[20] F. Paz, Bone cements reinforced with carbon based nanomaterials, Universidad Pontificia de Comillas, 2017.

[21] J. Orellana, Hip prosthesis: Redesign of the femoral stem and cement, Universidad Politécnica de Madrid, 2018 .

[22] J. Perek, R.M. Pilliar, "Fracture toughness of composite acrylic bone cements," J. Mat. Sci.: Materials in Medicine, vol. 3, no. 1, p. 333-344, 1992.

[23] G. Frutos, J.Y. Pastor, N. Martínez, M.R. Virto, S. Torrado, "Influence of lactose addition to gentamicin-loaded acrylic bone cement on the kinetics of release of the antibiotic and the cement properties," Acta Biomater., vol. 6, no. 3, pp. 804-11, 2010.

[24] R. Vaishya, M. Chauhan, A. Vaish, "Bone cement," J. Clin. Orthop. Trauma., vol. 4, no. 4, pp. 157-63, 2013.

[25] T. Palacios, S. Tarancón, C. Abad, J.Y. Pastor, "Saliva Influence on the Mechanical Properties of Advanced CAD/CAM Composites for Indirect Dental Restorations," Polymers, vol. 13, no. 5, pp. 808-22, 2021.

[26] Y.Y. Pastor, J. Orellana, M. Sánchez, F. Calle, J.Y. Pastor, "Physical-Mechanical Behaviour and Processing Evolution of PMMA Bone Cement due to Graphene Addition, ," Biomed. J. Sci. Tech. Res., vol. 35, no. 1, pp. 273124, 2021.

[27] S. Timoshenko, Strength of materials, third edition, D. Van Nostrand Company, 1955.

[28] G.V. Guinea, J.Y. Pastor, J. Planas, "Stress Intensity factor, compliance and CMOD for a General Three-Point-Bend Beam," Int. J. Fract., vol. 89, no. 10, pp. 103-116, 1988.

[29] S.S: Gosavi, S.Y. Gosavi, R.K. Alla, "Local and Systemic Effects of Unpolymerised Monomers," Dent. Res., vol. 7, no. 2, p. 82-87, 2010.

[30] 